\title{
25 Research Suare \\ Synthesis and Characterization of SrHfO3 Co-doped with Gd2O3 and Yb2O3 (SHGY)
}

Hemalatha Kandi ( $\square$ hemalathakandi2014@gmail.com )

Andhra University College of Engineering https://orcid.org/0000-0002-3705-4278

Prof.Ramji Koona

Andhra University College of Engineering

G.M.J Raju

Andhra University College of Engineering

\section{Research Article}

Keywords: Mechanical solid-state synthesis, Spark Plasma Sintering (SPS), perovskites, Thermal Expansion Coefficient (CTE)

Posted Date: November 18th, 2020

DOI: https://doi.org/10.21203/rs.3.rs-106303/v1

License: (c) (1) This work is licensed under a Creative Commons Attribution 4.0 International License. Read Full License 


\section{Abstract}

A new material SHGY is obtained after synthesizing $\mathrm{SrHfO}_{3}$ co-doped with rare earth oxides ( $5 \mathrm{~mol} \% \mathrm{Gd}_{2} \mathrm{O}_{3}$ and $5 \mathrm{~mol} \% \mathrm{Yb}_{2} \mathrm{O}_{3}$ ). This process is carried out by a mechanical solid-state synthesis method. The synthesized powder is annealed at $1450^{\circ} \mathrm{C}$ keeping rate of increase of $3^{\circ} \mathrm{C} / \mathrm{min}$ for 2 hours. The phase and structural information of synthesized powder is characterized by X-Ray Diffraction (XRD) technique. The powder sample is sintered by Spark Plasma Sintering (SPS) at $1700^{\circ} \mathrm{C}$ for 15 minutes to form into a pellet. The microstructure analysis is done by using Field Emission Scanning Electron Microscopy (FESEM) followed by composition analysis by Energy Dispersive Spectroscopy (EDS). The phase purity is examined by Thermal Gravimetric Analysis and Differential Thermal Analysis (TG-DTA) and studies conclude that weight loss is $<3 \%$ and there are no changes in phase transformation. Finally, Thermal Expansion Coefficient (CTE) is studied by a Dilatometer. Results stated there is an increase in the CTE in the range of $8.82-13.0 \times 10^{-6} \mathrm{~K}^{-1}$ calculated temperature range $100-1000^{\circ} \mathrm{C}$. This result of CTE showed there is a $19.2 \%\left(10.5 \times 10^{-6} \mathrm{~K}^{-1}\left(200-1100^{\circ} \mathrm{C}\right)\right)$ increase compared to the YSZ. This aids in the reduction of thermal mismatches between the substrate and topcoat in Thermal barrier applications (TBC).

\section{Introduction}

Generally, Thermal insulation coatings are the most complex structures. To reduce these complexity Thermal Barrier Coatings (TBC) are used. These coatings also improve performance, efficiency and longer component life times of the metallic substrates. Nowadays, researchers aimed at developing the coatings for the application of a jet engine, aircrafts, gas turbine blades and vanes etc., [1-3]. In TBC's, ceramic materials are coated on the substrate and this coated is treated as a topcoat layer. Material should possess a good number of predominant properties for instance phase stability, high thermal expansion coefficient $\left(>9 \times 10^{-6} \mathrm{~K}^{-1}\right)$, low thermal conductivity $\left(<2 \mathrm{~W} \cdot \mathrm{m}^{-1} \cdot \mathrm{K}^{-1}\right)$, high fracture toughness and low sintering rate to justify the properties of topcoat layer [4 \&13]. The standard ceramic materials like YSZ $\left(7-8 \% \mathrm{Y}_{2} \mathrm{O}_{3}\right.$ stabilized $\left.\mathrm{ZrO}_{2}\right)$ have low thermal conductivity, phase stability and chemically inert at a temperature below $1200^{\circ} \mathrm{C}$. Beyond this temperature, YSZ there are phase transformations that occur from t-tetragonal and cubic $(t+c)$ and finally changed to monoclinic $(m)$ structure. Due to this phase transformation, deposited YSZ showed a significant change in its volume which is noticeable. This change causes crack formation in the coatings, degradation of strain tolerance and accelerated sintering for high temperatures [4-5]. To overcome this problem, researchers are executing new TBC materials or doping in the present material which can satisfy the TBC requirements which are mentioned above.

Recently, perovskites $\left(\mathrm{ABO}_{3}\right)$ materials have been considered as a substitute for $\mathrm{YSZ}$ top coat for TBC applications. The $\mathrm{Sr}$ series perovskites like $\mathrm{SrZrO}_{3}$ [6-9], $\mathrm{SrHfO}_{3}$ [10-11], $\mathrm{SrTiO}_{3}$ [15], $\mathrm{SrMoO}_{3}$ [15], $\mathrm{SrRuO}_{3}[11], \mathrm{SrCeO}_{3}[12 \& 15]$ are studied till now. Materials which sustain high melting points are suitable for these applications, among the above mentioned materials $\mathrm{SrHfO}_{3}$ have high melting point (3200K) 
[15]. Kennedy, examined the phase transformation of $\mathrm{SrHfO}_{3}$ by high resolution neutron powder diffraction method and reported as follows [10-11]:

Orthorhombic $\left(700^{\circ} \mathrm{C}\right) \rightarrow$ pseudo-tetragonal $\left(830^{\circ} \mathrm{C}\right) \rightarrow$ tetragonal $\left(1170^{\circ} \mathrm{C}\right) \rightarrow$ Cubic

Previous studies on $\mathrm{SrHfO}_{3}$ primarily emphasis [13-16] the thermal and mechanical properties. From these results they concluded thermal conductivity is $5.2 \mathrm{~W} / \mathrm{m} . \mathrm{K}$ at room temperature which is compared with the theoretical studies [11]. This is too high compared to the TBC requirements, thus giving a negative influence for these applications. To overcome these problems further research has been done by adding dopants materials in $\mathrm{SrHFO}_{3}$. By this thermal conductivity is reduced leaving no change in the thermal expansion coefficient (CTE) between topcoat and substrate [17-19]. Lesser valves of CTE lead to high thermal mismatches between the surfaces. To overcome this problem materials should be co-doped in $\mathrm{SrHfO}_{3}$. Selection of these dopant materials are most important. So, that this final material can increase the CTE for the TBC application.

Rare earth oxide materials viz., $\mathrm{Gd}_{2} \mathrm{O}_{3}$ and $\mathrm{Yb}_{2} \mathrm{O}_{3}$ and combinations of these materials in $\mathrm{SrHfO}_{3}$ may have been suitable for TBC applications. Phonon mean free path is inversely proportional to the square of the atomic weight difference between the solute. By choosing low valves of Phonon mean free path leads to the reduction of thermal conductivity. $\mathrm{Gd}(157.25 \mathrm{u}), \mathrm{Yb}(173.04 \mathrm{u})$ and $\mathrm{Hf}(178.49 \mathrm{u})$ has low phonon mean free path when doped in SrHfO3. This satisfies the above statement when compared to the $Y$ (88.9u) and $\mathrm{Zr}(99.224 \mathrm{u})$ doping in YSZ [20]. Still a lot of research is necessary to study the influence of rare earth oxide materials doping with $\mathrm{SrHfO}_{3}$.

The main objective of this paper is to synthesize Rare earth oxide materials $\left(\mathrm{Gd}_{2} \mathrm{O}_{3}\right.$ and $\left.\mathrm{Yb}_{2} \mathrm{O}_{3}\right)$ doped in $\mathrm{SrHfO}_{3}$ to form a new material SHGY by using mechanical solid state method. SHGY is annealed at $1450^{\circ} \mathrm{C}$ keeping a rate of increase of $3^{\circ} \mathrm{C} / \mathrm{min}$ for 2hours and characterized by XRD to study the phase evaluation. The final powder is sintered by using spark plasma sintering (SPS). This helps in converting powder into a pellet. The phase stability and thermal properties such as thermal expansion coefficient and surface morphology are characterized by using TG-DTA, Dilatometer and FESEM respectively.

\section{Experimental Procedure}

\subsection{Chemicals used for synthesis}

$\mathrm{SrCO}_{3}\left(\geq 99.9 \%\right.$, Sigma-Aldrich, USA), $\mathrm{HfO}_{2}$ (Sigma-Aldrich, USA), $\mathrm{Yb}_{2} \mathrm{O}_{3}(99.99 \%$ Ultra nanotech Pvt. Ltd) and $\mathrm{Gd}_{2} \mathrm{O}_{3}(99 \%$, Ultra nanotech Pvt. Ltd).

\subsection{Synthesis of SHGY powder}

SHGY powder was prepared by choosing $\mathrm{SrCO}_{3}, \mathrm{HfO}_{2}, 5 \mathrm{~mol} \% \mathrm{Gd}_{2} \mathrm{O}_{3}, 5 \mathrm{~mol} \% \mathrm{Yb}_{2} \mathrm{O}_{3}$ mixed in a ball mill zirconium jar in the presence of methanol by a mechanical solid- state method taking balls to powder ratio 1:10. The powders were milled for one hour maintaining speed with $500 \mathrm{rpm}$ throughout the milling 
to get a homogeneous mixing. Then the mixed powder was annealed in alumina crucible at $1450^{\circ} \mathrm{C}$ for 24 hours with a rate of increase $3 \% \mathrm{C}$ in furnace to decompose the carbonates of $\mathrm{SrCO}_{3}$ from these powders. In order to obtain the single phase material, the synthesis process was repeated for three times.

\subsection{Sintering procedure for preparing pellet using Spark Plasma Sintering (SPS)}

The obtained synthesized powder was sintered by using SPS technique by using graphite die and a punch. Figure 1 shows the schematic representation of the SPS procedure to convert the powder into a pellet. The synthesized SHGY powder is poured into the graphite die with dimensions of $20 \mathrm{~mm}$ inner diameter. In order to separate the powder from graphite punch surfaces, graphite foil was used. Sintering was carried out at the temperature of $1700^{\circ} \mathrm{C}$ in a vacuum atmosphere at applied pressure of $50 \mathrm{Mpa}$ with a heat rate $100^{\circ} \mathrm{C} \mathrm{min}^{-1}$ and maintained $15 \mathrm{~min}$ holding time and followed by the cooling rate at $150^{\circ} \mathrm{Cmin}^{-1}$. SPS temperature was measured by using a thermocouple at a hole drilled in the die which was placed $4 \mathrm{~mm}$ away from the sample. Then the experiment was conducted by applying vacuum pressure, initially at $15 \mathrm{MPa}$ onto the powder and then it was gradually increased to a maximum of 50MP. When the pressure has reached the sintering temperature then the maximum applied pressure is applied during sintering holding time. Finally, the outcome of the pellet was in $20 \mathrm{~mm}$ diameter with $3 \mathrm{~mm}$ thickness. During the SPS process, chamber vacuum pressure and temperature values were recorded and plotted against time as shown in Fig. 2.

\section{Characterization Of Shgy}

The X-ray diffraction (XRD) (Model XPERT-PRO) characterization technique is used for phase analysis of the synthesized powder at a wavelength of $1.5406 \mathrm{~A}^{\circ}$ using $\mathrm{Cu}-\mathrm{Ka}$ ray at $30 \mathrm{kV}$ with the scan range 10$80^{\circ}(2 \theta)$. The obtained graph was validated with X'pert High score plus software. The powder SHGY is sintered by Spark Plasma Sintering (SPS) for making pellet. Through Archimede's technique, the density of the pellet was measured by using a Densitometer. The phase stability of the material was recorded from $30^{\circ} \mathrm{C}$ (room temperature) to $1130^{\circ} \mathrm{C}$ in nitrogen gas atmosphere at $10^{\circ} \mathrm{C} / \mathrm{min}$ rate of increase by using TG-DTA equipment. The Coefficient of thermal expansion (CTE) was characterized by a Dilatometer (VBCRC lab) from $30^{\circ} \mathrm{C}$ (room temperature) to $1000^{\circ} \mathrm{C}$ at an increase rate of $10^{\circ} \mathrm{C}$. The microstructure and elemental analysis of the sintered pellet was investigated by Field Emission Scanning Electron Microscopy (FESEM) (JEOL) for this $10 \mathrm{kV}$ accelerated voltage. Elemental analysis by Energy Dispersive X-ray Spectroscopy (EDS).

\section{Results And Discussion}

\subsection{XRD characterization of synthesis powder (SHGY)}

XRD characterization is done for the synthesized powder $\mathrm{SHGY}$ was annealed at $1450^{\circ} \mathrm{C}$ temperature and $3^{\circ} \mathrm{C} / \mathrm{min}$ rate of increase for 24 hours for 3 times to form a single phase. The obtained XRD pattern of 
SHGY compared with the standard pattern of orthorhombic $\mathrm{SrHfO}_{3}$ PDF code 00-045-0211 and the results is also validated with X'pert High score software and observed the same with the literature [19]. This result can be appreciated that no intermediate phase has been noticed, all the peaks in the XRD data reflects $\mathrm{SrHfO}_{3}$ phase. XRD pattern of SHGY shown in Fig. $3(a-b)$ from the result, maximum peak

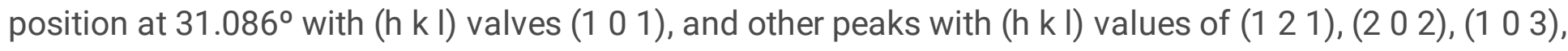
(3 2 1) and (2 4 2) respectively. Because of that annealing temperature and the bigger ionic radius of $\mathrm{Gd}^{+}$ ${ }^{3}\left(0.94 \mathrm{~A}^{\circ}\right)$ and $\mathrm{Yb}^{+3}\left(0.84 \mathrm{~A}^{\circ}\right)$ compared to the $\mathrm{Hf}^{+4}\left(0.71 \mathrm{~A}^{\circ}\right)$ the doping of $\mathrm{Gd}_{2} \mathrm{O}_{3}$ and $\mathrm{Yb}_{2} \mathrm{O}_{3}$ were done properly with $\mathrm{SrHfO}_{3}[19 \& 20]$. Figure 3 (b) shows that $\mathrm{SHGY}$ is formed fully without any other secondary phases.

The SHGY powder sample is sintered by the SPS method to make a pellet. Bulk density $(\rho)$ of pellet is $7.5 \mathrm{~g} / \mathrm{cm}^{3}$ with the relative density of $95.1 \%$ and the fractional porosity is $4.9 \%$ is measured by Archimede's technique by a densitometer from Eq. (1). Table.1 shows the bulk density, relative density and fractional porosity results which are in good agreement with the XRD powder density $\left(7.74 \mathrm{~g} / \mathrm{cm}^{3}\right)$ results.

Fractional porosity $(\%)=1$-Relative density (\%) Eq. (1)

Table 1

Bulk density, Relative density and fractional porosity of the sintered pellet

\begin{tabular}{|llll|}
\hline Material & Bulk Density $(\rho)\left(\mathrm{g} / \mathrm{cm}^{3}\right)$ & Relative Density (\%) & Fractional Porosity (\%) \\
\hline SHGY & 7.5 & 95.1 & 4.9 \\
\hline
\end{tabular}

FESEM technique helps to view the surface morphology of SHGY pellet surface. As the material is ceramic, the FESEM is characterized for conductive materials. Firstly, the gold film was coated on the nonconductive material SHGY pellet surface which helps electrons pass into the SHGY by conductive surface. The grain boundaries are formed due to sintering which is absorbed from the micrograph clearly shown in Fig. 4 (a) Fig. 4 (b) at 10 kV and 15 kV respectively measured at 33000X and 30000X magnification respectively. The grain size measured is the range of $68-77 \mathrm{~nm}$ and observed the grains are bounded tightly without any voids. The elements which were presented in the pellets were $\mathrm{Sr}, \mathrm{Hf}, \mathrm{Gd}$, $\mathrm{Yb}$, and $\mathrm{O}$ confirmed by the EDS as shown in Fig. 4 (c). The peaks of $\mathrm{Sr}, \mathrm{Hf}, \mathrm{Gd}, \mathrm{Yb}$, and $\mathrm{O}$ shows perfect doping is done. It was clearly shown that there are no other element peaks present in the spectrum that conclude that there are no impurities present in the pellet and the whole pellet is SHGY in single phase.

\subsection{TG-DTA characterization of SHGY}

To further strengthen our earlier observations about phase stability, a systematic TG-DTA study of the prepared sintered SHGY was carried out from room temperature to $1130^{\circ} \mathrm{C}$ in a nitrogen gas atmosphere with $10^{\circ} \mathrm{C} / \mathrm{min}$ rate of increase as shown in Fig. 5 . The TG plot shows the weight loss is in three steps 
attributable to (i) Dehydration, which can caused by the absorbed moisture weight loss of $2 \%$ at about $100^{\circ} \mathrm{C}$ [21] (ii) Decomposition, low molecular weight compounds such as additives, crystallization water and first decomposition products such as intermediate carbonate and (iii) Finally weight loss of $<3 \%$ at $970^{\circ} \mathrm{C}$ in the plot. Thereafter from the DTA plot no abnormal changes occur during the process means that there is no entropy change, which implies that no organic matter is present in the sample and combustion is completed. There are no peaks observed for any considerable phase transition taking place in the sample up to this temperature.

\subsection{Thermal expansion coefficient (CTE) of SHGY}

The Coefficient of thermal expansion (CTE) of the SHGY is a significant property for influencing the durability of TBC when increasing temperature from lower to higher. The residual stresses developed between the substrate and the topcoat material due to the mismatch of the CTE. In this present work, the CTE was measured by the dilatometer in the presence of nitrogen gas with a $10^{\circ} \mathrm{C}$ rate of increase and measured from room temperature to $1000^{\circ} \mathrm{C}$. The obtained graph was increased linearly and values range from $8.82-13.1 \times 10^{-6} \mathrm{~K}^{-1}\left(100-1000^{\circ} \mathrm{C}\right)$ as depicted in Fig. 6 which is high as compared with $\mathrm{SrHfO}_{3}$ and also for $\mathrm{YSZ}$ [17\& 22]. During measurement there are no abnormal changes, indicating that enhance the phase stability and increase the CTE because of co-doping rare earth oxides $\mathrm{Gd}_{2} \mathrm{O}_{3}$ and $\mathrm{Yb}_{2} \mathrm{O}_{3}$.

\section{Conclusion}

Rare earth oxides such as $\mathrm{Gd}_{2} \mathrm{O}_{3}$ and $\mathrm{Yb}_{2} \mathrm{O}_{3}$ co-doping with $\mathrm{SrHfO}_{3}(\mathrm{SHGY}$ ) influence on the phase stability and thermal properties was investigated. The conclusions draw from the work are as follows:

- SHGY was successfully synthesized by a mechanical solid-state method and it has a good phase stability which was characterized by XRD and validated with standard data.

- Powder sample was sintered at $1700^{\circ} \mathrm{C}$ temperature by using SPS, resulting with relative density is $95.1 \%$ of bulk density and fractional porosity is $4.9 \%$.

- The microstructure of grain boundaries and the elemental compounds of SHGY pellet were observed by using FESEM and EDS. The grain size is in the range of $68-77 \mathrm{~nm}$.

- Phase purity was examined by TG-DTA from these results and concluded that the weight loss is less than $3 \%$, and there is no phase transformation observed that means there is no phase transformation occurred.

- SHGY shows excellent phase stability up to $1700^{\circ} \mathrm{C}$ sintering temperature which is achieved by adding co-doping of $\mathrm{Gd}_{2} \mathrm{O}_{3}$ and $\mathrm{Yb}_{2} \mathrm{O}_{3}$ and this is superior to $\mathrm{YSZ}$.

- The CTE is also increased $19.2 \%$ increased compare to the $\mathrm{SrHfO}_{3}$ e. $\left(8.82-13.0 \times 10^{-6} \mathrm{~K}^{-1}\left(100-1000^{\circ} \mathrm{C}\right)\right.$. These causes reduce the thermal mismatches between the substrate and topcoat in the thermal barrier applications whereas in gas turbine blades, vanes etc. 


\section{Declarations}

\section{Acknowledgement}

The authors gratefully acknowledge the financial support from TEQIP-II through the Ministry of Human Resource Development, Andhra University college of engineering(A), Andhra University, Visakhapatnam, and Andhra Pradesh, INDIA.

\section{References}

1. R.A.Miller (1987) "Current status of thermal barrier coatings- An overview" Surface and Coatings Technology, 30(1), 1-11, doi: 10.1016/0257-8972(87)90003-x

2. R.A.Miller (1997) "Thermal barrier coatings for aircraft engines: history and directions" Journal of Thermal Spray Technology, 6(1), doi: 10.1007/bf02646310, 35-42

3. N.P.Padture (2002) "Thermal Barrier Coatings for Gas-Turbine Engine Applications" Science, 296(5566), 280-284, doi:10.1126/science.1068609

4. D.Stoever RVassen \& X.Q.Cao (2004) Ceramic materials for thermal barrier coatings. J Eur Ceram Soc 24(1):1-10. doi:10.1016/s0955-2219(03)00129-8

5. Clarke DR, Oechsner M, Padture NP (2012) Thermal-barrier coatings for more efficient gas-turbine engines. MRS Bull 37(10):891-898. doi:10.1557/mrs.2012.232

6. Cordfunke EHP, Roosmalen JAMVan, van Vlaanderen P (1992) On the structure of SrZrO3. J Solid State Chem 101(1):59-65. doi:10.1016/0022-4596(92)90200-f

7. Carlsson L (1967) High-temperature phase transitions in SrZrO3. Acta Crystallogr A 23(6):901-905. doi:10.1107/s0365110x67004013

8. Kennedy BJ, Howard CJ, Kisi EH, Knight KS (2000) The structural phase transitions in strontium zirconate revisited. J Phys: Condens Matter 12(45):L677-L683. doi:10.1088/0953-8984/12/45/101

9. Kennedy BJ, Chakoumakos BC, Howard CJ (1999) High-temperature phase transitions in $\mathrm{SrZrO}_{3}$. Phys Rev B 59(6):4023-4027. doi:10.1103/physrevb.59.4023

10. Kennedy BJ, Chakoumakos BC, Howard CJ (1999) High-temperature phase transitions in $\mathrm{SrHfO}_{3}$. Phys Rev B 60(5):2972-2975. doi:10.1103/physrevb.60.2972

11. Muta H, Kurosaki K, Kobayashi S, Yamanaka S, Maekawa T, Matsuda T (2004) Thermophysical properties of $\mathrm{SrHfO}_{3}$ and $\mathrm{SrRuO}_{3}$. J Solid State Chem 177(10):3484-3489.

doi:10.1016/j.jssc.2004.05.039

12. Muta H, Kurosaki K, Uno M, Yamanaka S, Oyama T, Matsuda T (2005) Thermophysical Properties of Perovskite-Type Strontium Cerate and Zirconate. J Am Ceram Soc 88(6):1496-1499. doi:10.1111/j.1551-2916.2005.00278.x 
13. Vali R (2008) Structural phases of $\mathrm{SrHfO}_{3}$. Solid State Commun 148(1-2):29-31. doi:10.1016/j.ssc.2008.07.018

14. Muta H, Kurosaki K, Kobayashi S, Yamanaka S, Maekawa T, Matsuda T (2004) Thermal and mechanical properties of $\mathrm{SrHfO}_{3}$. J Alloy Compd 381(1-2):295-300.

doi:10.1016/j.jallcom.2004.03.113

15. Kurosaki K, Uno M, Yamanaka S, Kobayashi S, Maekawa T, Matsuda T (2005) Thermochemical and thermophysical properties of alkaline-earth perovskites. J Nucl Mater 344(1-3):61-66. doi:10.1016/j.jnucmat.2005.04.017

16. Feng L, Liu Q, Liu Z (2012) “Structural, elastic and mechanical properties of orthorhombic $\mathrm{SrHfO}_{3}$ under pressure from first-principles calculations" Physica B, 407(12), doi:10.1016/j.physb.2012.01.130

17. Ma W, Li P, Dong H, Bai Y, J.Zhao \& X.Fan (2013) $\mathrm{Y}_{2} \mathrm{O}_{3}$ and $\mathrm{Yb}_{2} \mathrm{O}_{3}$ Co-doped Strontium Hafnate as a New Thermal Barrier Coating Material. J Therm Spray Technol 23(1-2):154-159. doi:10.1007/s11666-013-0006-9

18. Kurosaki K, Yamanaka S, Maekawa T (2006) Thermal and mechanical properties of perovskite-type barium hafnate. J Alloy Compd 407(1-2):44-48. doi:10.1016/j.jallcom.2005.06.030

19. Ma W, Ren Y, Jin XL, Liang YH, Chen BD, Dong HY (2015) Thermophysical Properties of $\mathrm{Gd}_{2} \mathrm{O}_{3}$ Doped $\mathrm{SrHfO}_{3}$ Ceramic. Mater Sci Forum 816:237-241. doi:10.4028/www.scientific.net/msf.816.237

20. Guo H, Zhang H, Guo L, Gong S, Yang Y, Zhang $Y$ (2012) Influence of $\mathrm{Gd}_{2} \mathrm{O}_{3}$ and $\mathrm{Yb}_{2} \mathrm{O}_{3}$ Co-doping on Phase Stability, Thermo-physical Properties and Sintering of 8YSZ. Chin J Aeronaut 25(6):948-953. doi:10.1016/s1000-9361(11)60466-4

21. Padma Kumar H, Thomas JK, Koshy J, Mathai KC, Solomon S (2010) Nanocrystalline $\mathrm{SrHfO}_{3}$ synthesized through a single step auto-igniting combustion technique and its characterization. $J$ Alloy Compd 508(2):532-535. doi:10.1016/j.jallcom.2010.08.112

22. Glabay MS, Grechanyuk MI, Ruban OK, Myloserdov OB, Prokhorenko SV, Lakiza SM, Redko VP (2018) "Thermal Barrier Coatings: Current Status, Search, and Analysis". Powder Metall Met Ceram 57(12):82-113. doi:10.1007/s11106-018-9958-0

\section{Figures}




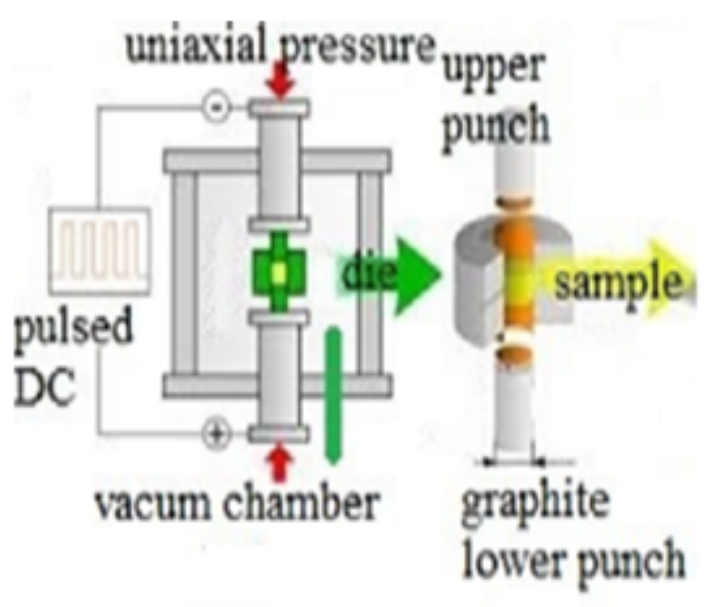

(a) Working of SPS

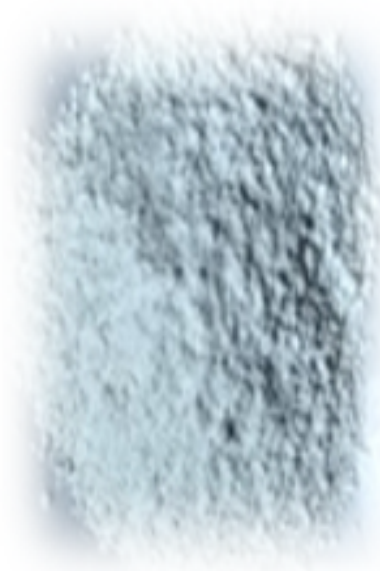

(b) Powder

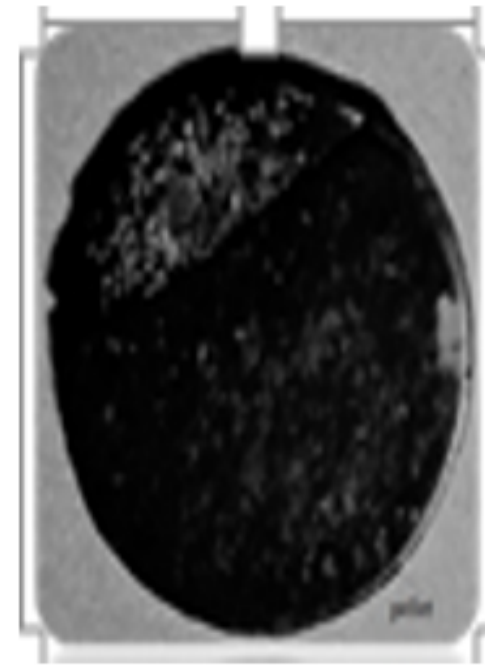

(c) Pellet

\section{Figure 1}

Schematic representation of the SPS procedure to covert powder to pellet of SHGY

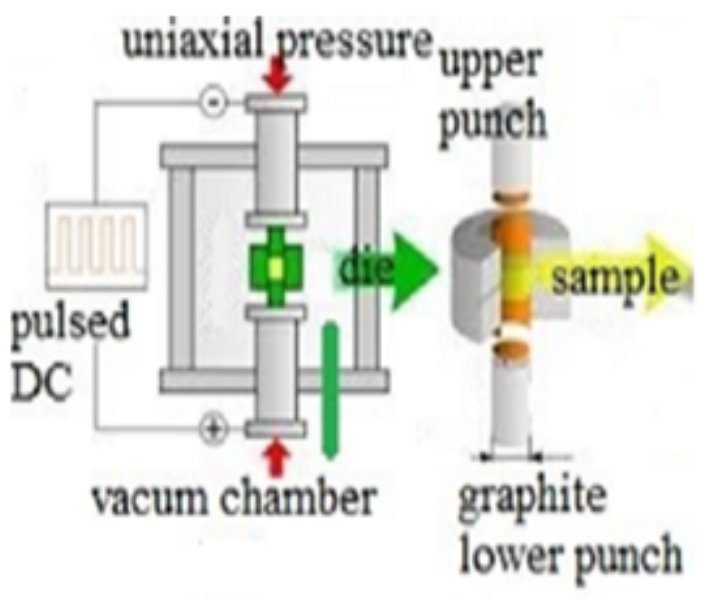

(a) Working of SPS

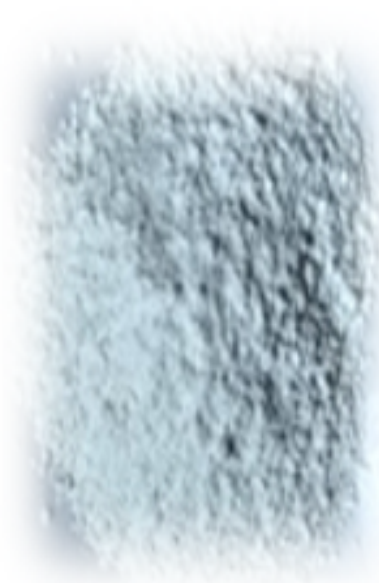

(b) Powder

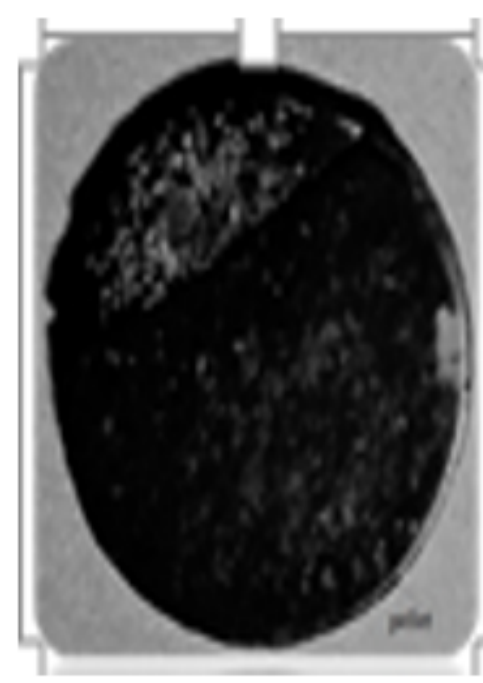

(c) Pellet

Figure 1

Schematic representation of the SPS procedure to covert powder to pellet of SHGY 


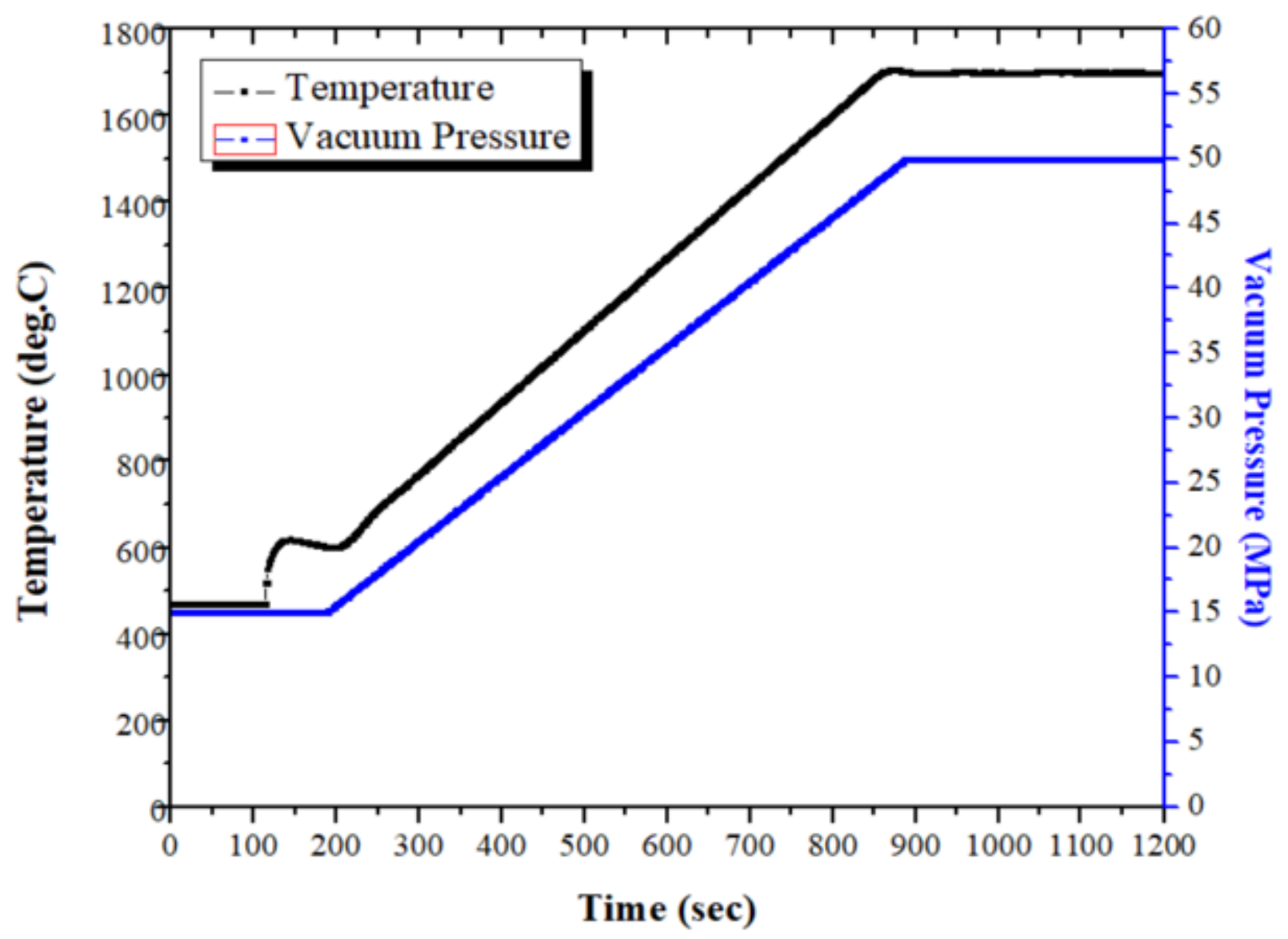

Figure 2

Vacuum pressure and temperature of the SPS chamber were plotted against time 


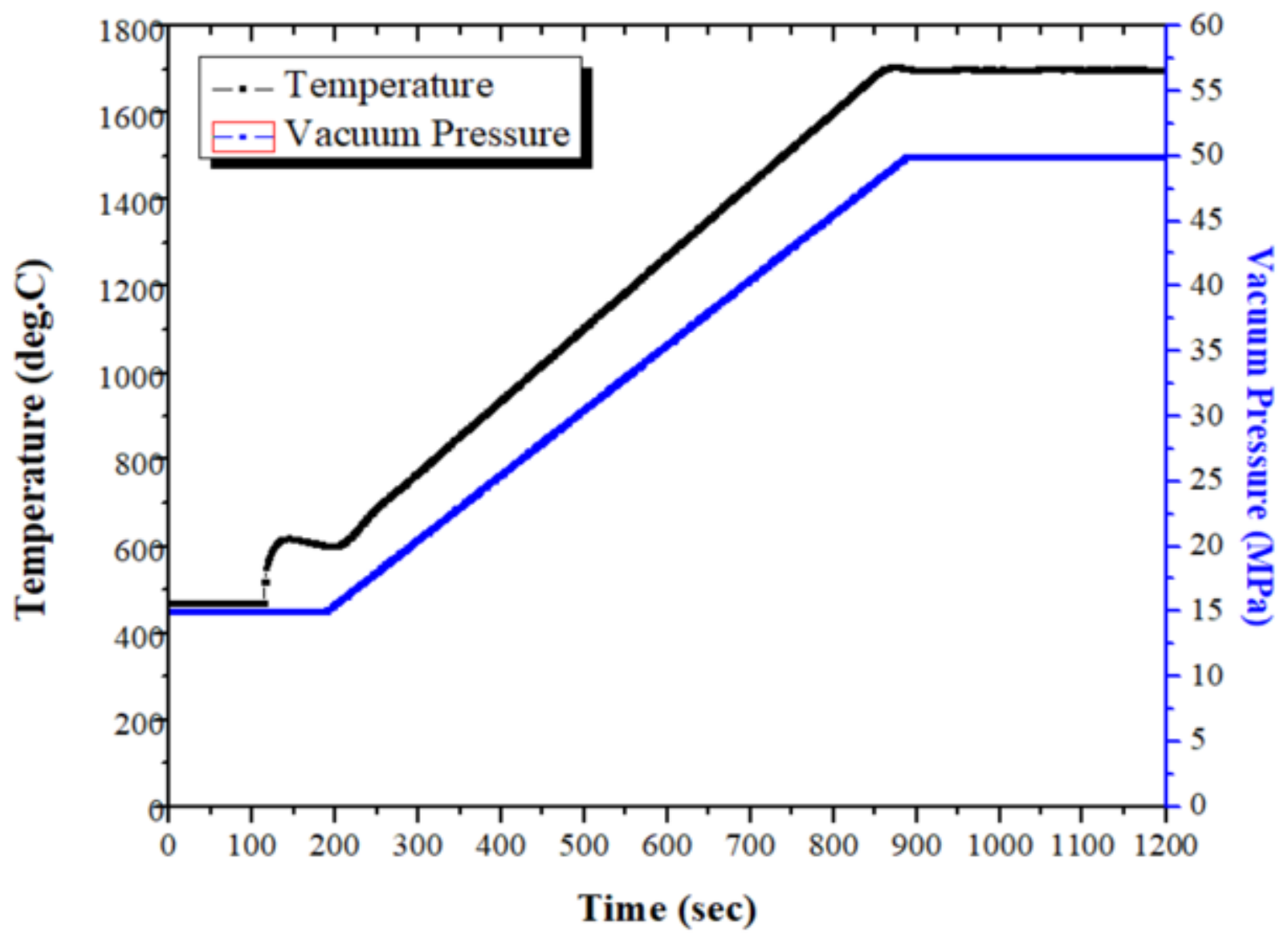

Figure 2

Vacuum pressure and temperature of the SPS chamber were plotted against time

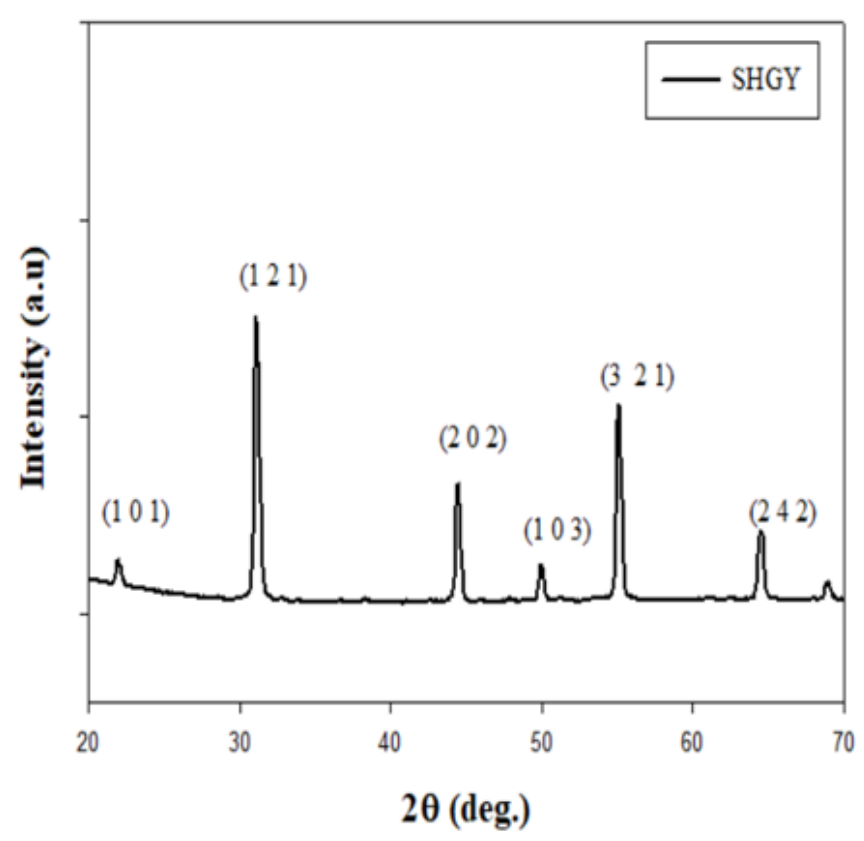

(a)

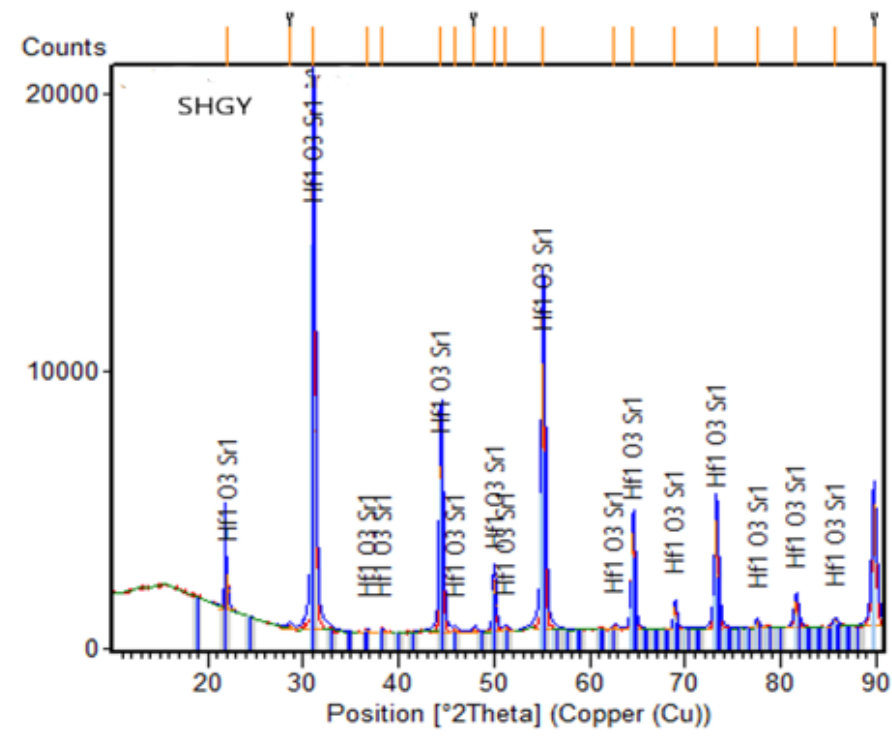

(b)

Figure 3 
(a-b). XRD patter of powder SHGY with (h k I) planes (b) 100\% single phase obtained and validated with PDFNo.00-045-0211

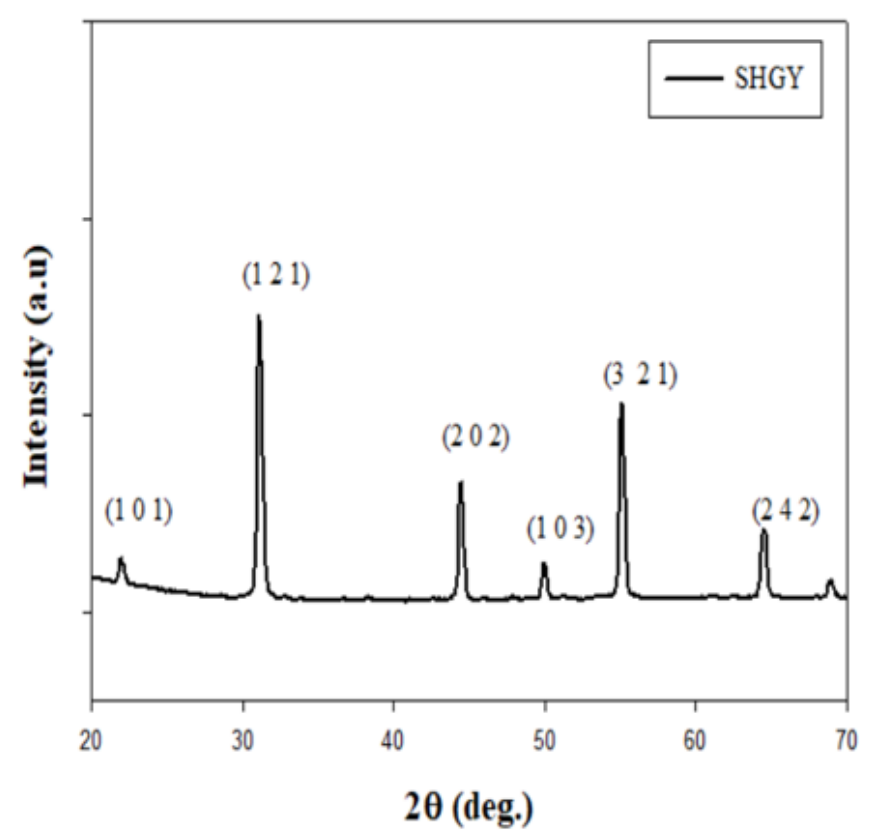

(a)

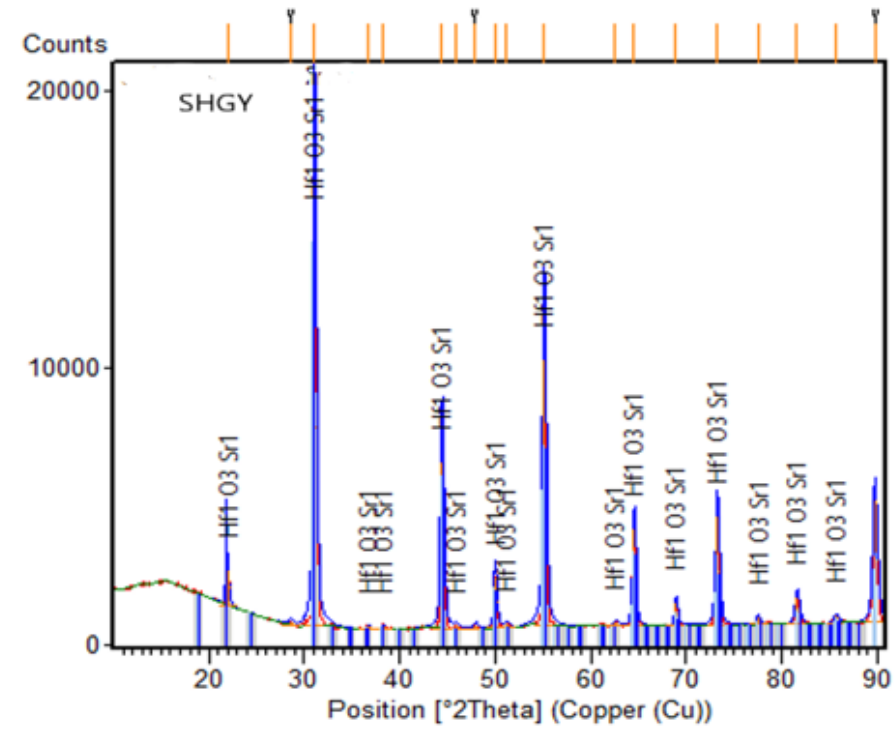

(b)

\section{Figure 3}

(a-b). XRD patter of powder SHGY with (h k I) planes (b) 100\% single phase obtained and validated with PDFNo.00-045-0211

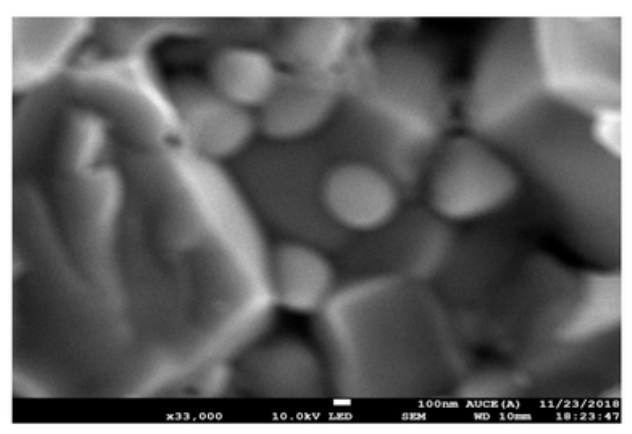

(a)

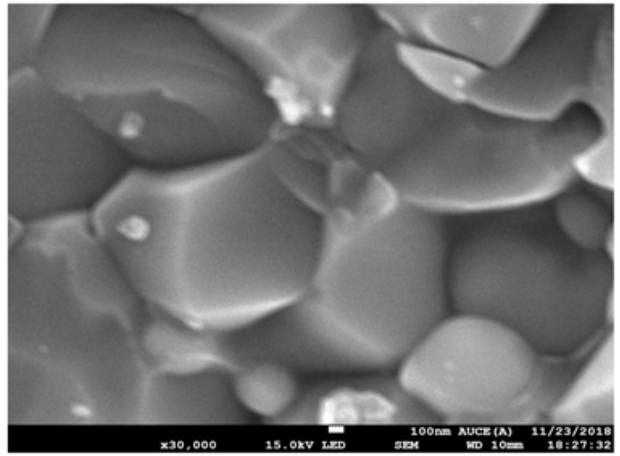

(b)

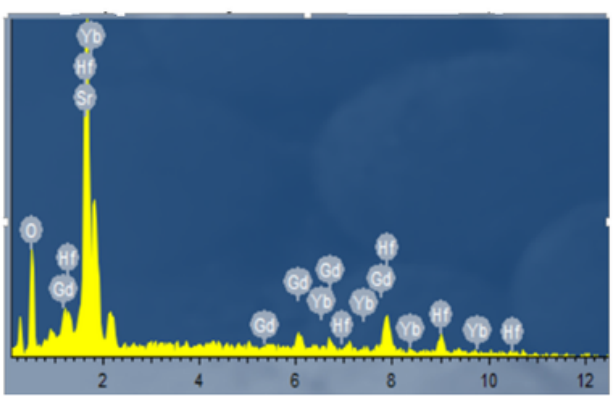

(c)

\section{Figure 4}

(a-c). Morphology and Elemental analysis of SHGY (a).Morphology of SHGY(10kV) (b).Morphology of SHGY (15kV) (c).Elemental analysis of SHGY pellet 


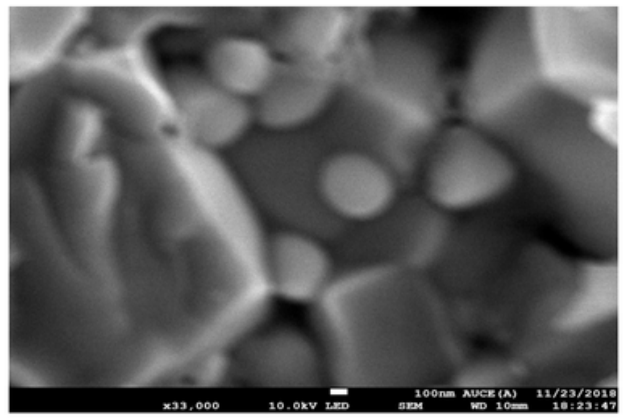

(a)

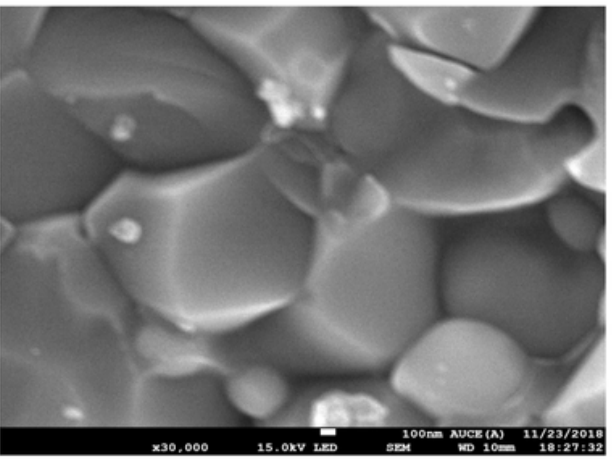

(b)

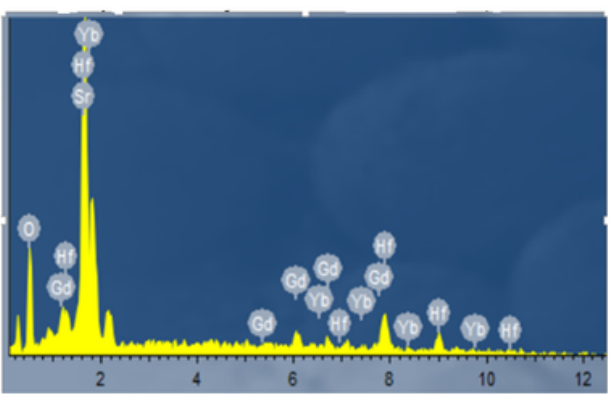

(c)

\section{Figure 4}

(a-c). Morphology and Elemental analysis of SHGY (a).Morphology of SHGY(10kV) (b).Morphology of SHGY (15kV) (c).Elemental analysis of SHGY pellet

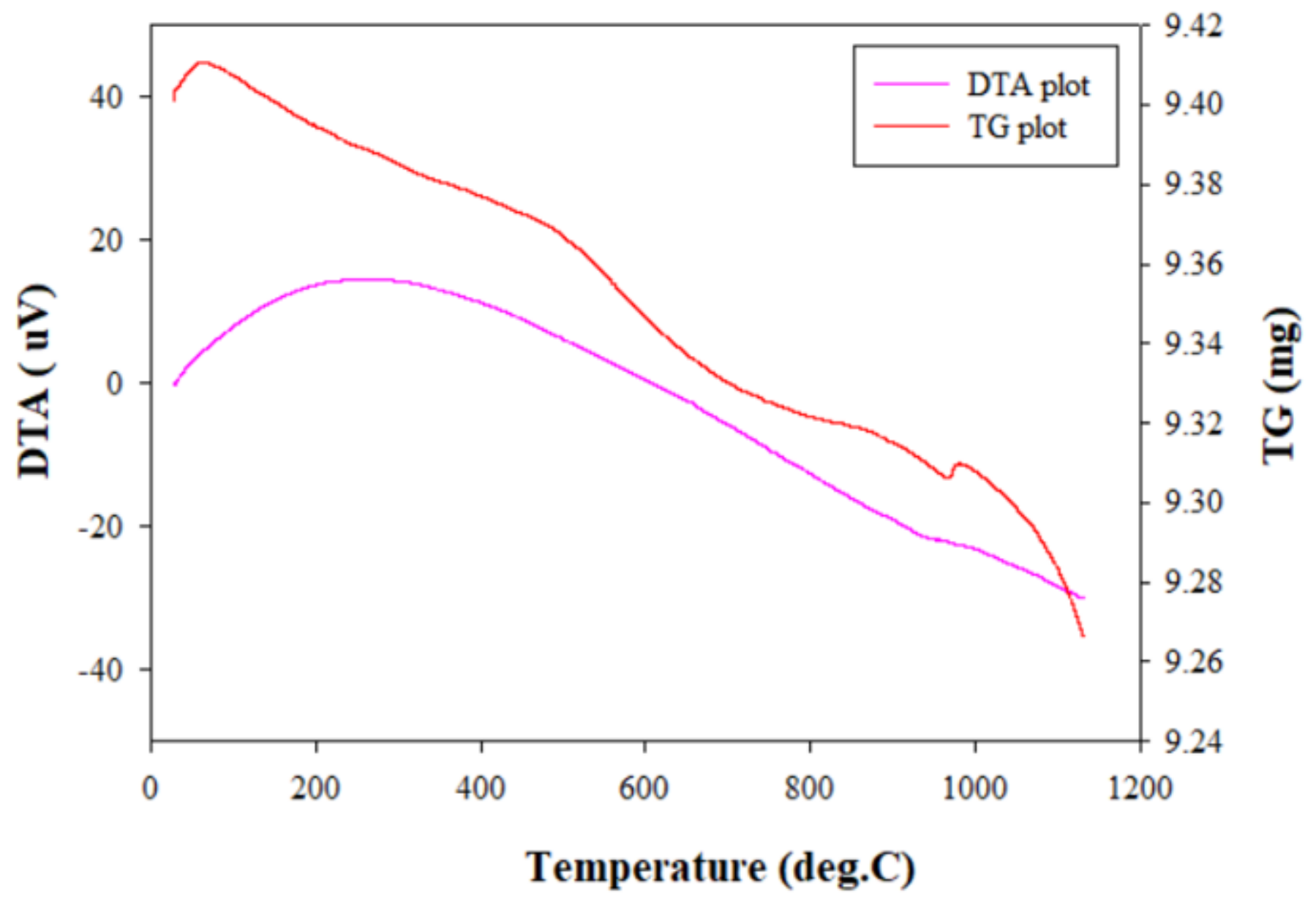

Figure 5

TG-DTA plot for sintered SHGY 


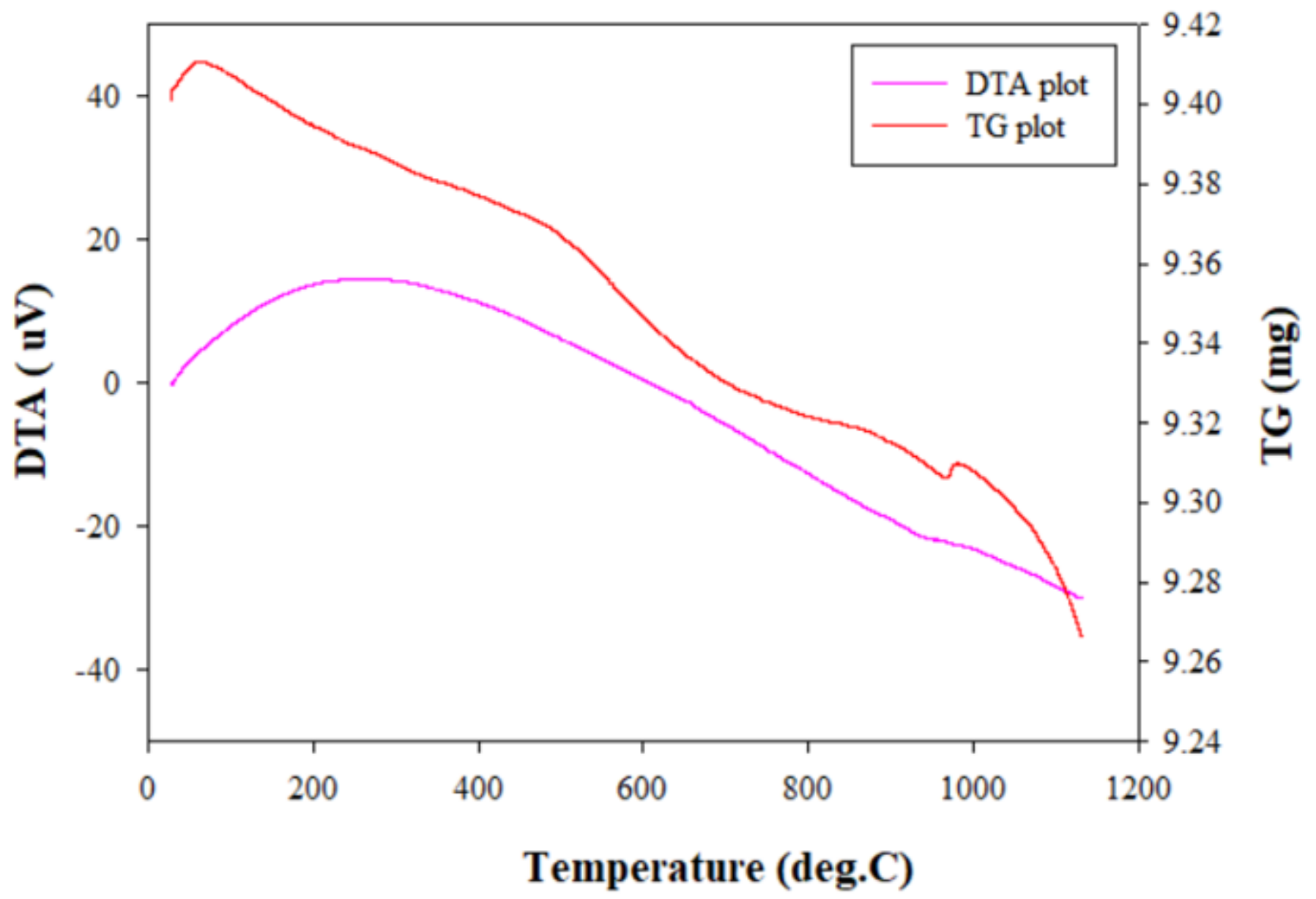

Figure 5

TG-DTA plot for sintered SHGY 


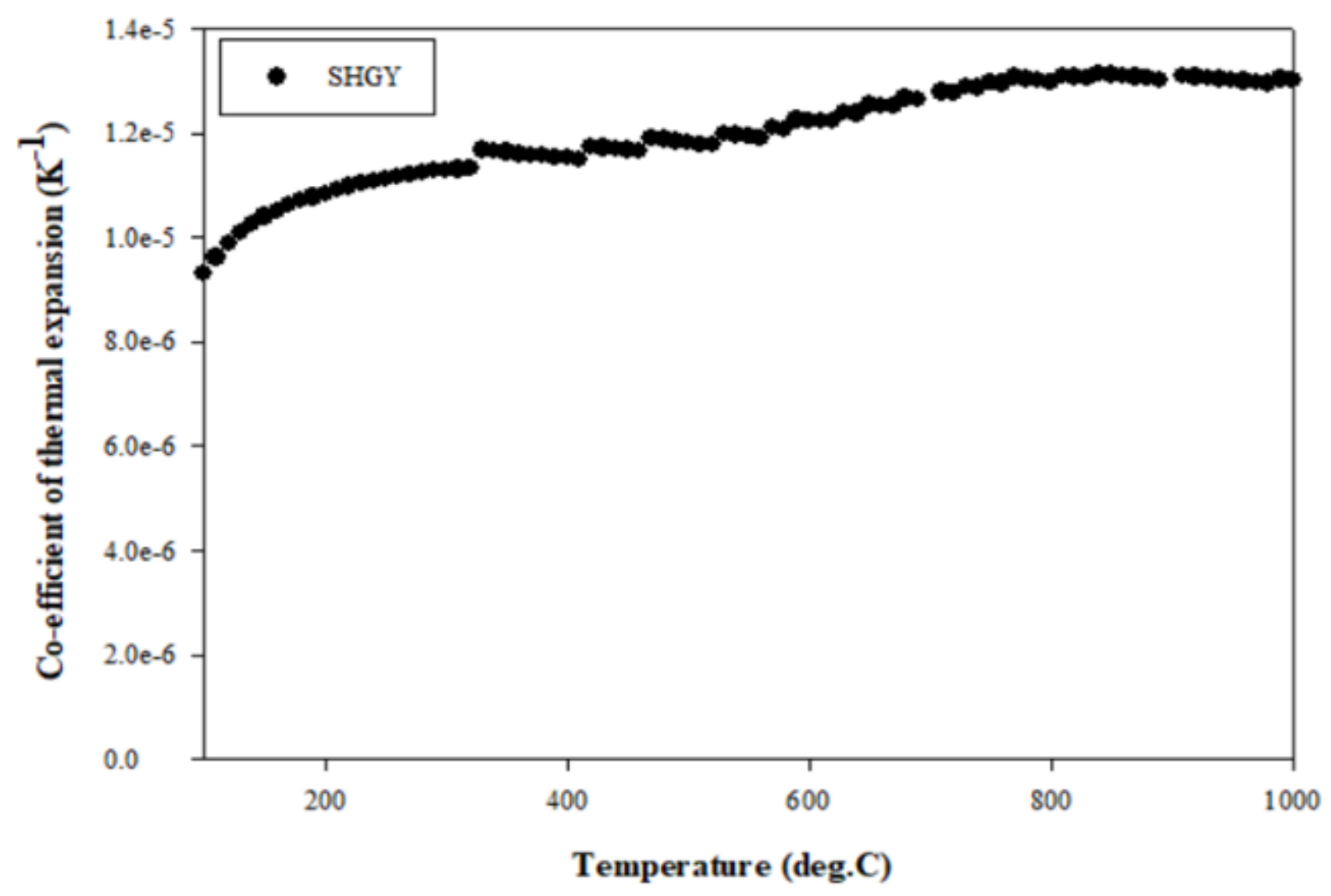

Figure 6

Thermal expansion plot of SHGY

Page 15/16 


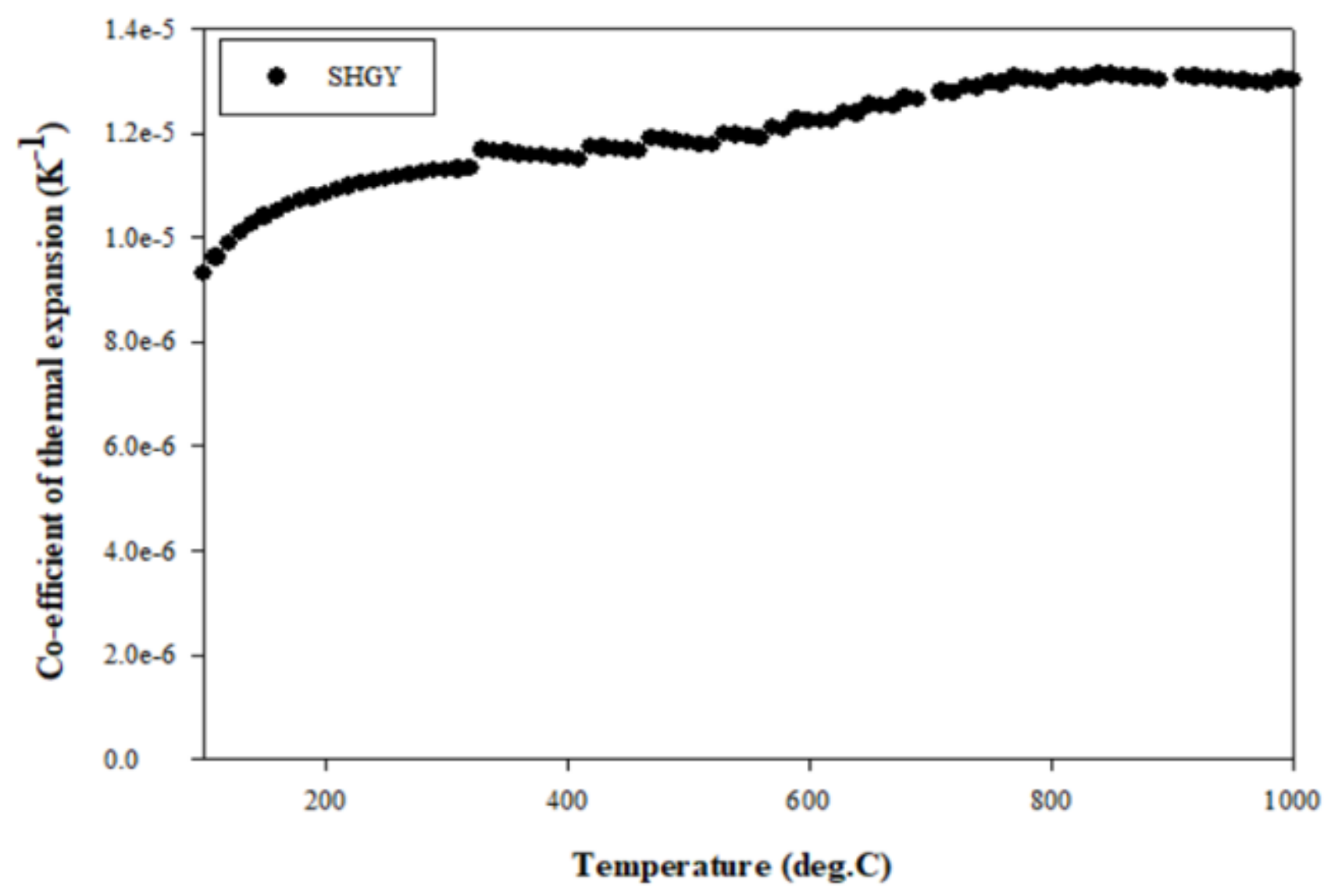

Figure 6

Thermal expansion plot of SHGY

Page 16/16 